\title{
Formação continuada de professores na Rede Municipal de Educação de Belo Horizonte: o que dizem as teses e dissertações (1986-2005) sobre o assunto?
}

\author{
In-service teacher education at Belo Horizonte \\ metropolitan school district: what do dissertations and \\ thesis (1986-2005) discuss about this issue?
}

\section{Júlio Emílio Diniz-Pereira ${ }^{[a]}$,Cláudia Caldeira Soares ${ }^{[\mathrm{b}]}$}

[a] Professor do Programa de Pós-Graduação em Educação da Universidade Federal de Minas Gerais (UFMG), Belo Horizonte, MG - Brasil, e-mail: juliodiniz@ufmg.br

${ }^{[b]}$ Rede Municipal de Educação de Belo Horizonte e Universidade Presidente Antônio Carlos (UNIPAC), Belo Horizonte, MG - Brasil, e-mail: claudia_caldeira@uol.com.br

\section{Resumo}

Este artigo procurou analisar as teses e dissertações produzidas, entre 1986 e 2005, sobre a Rede Municipal de Educação de Belo Horizonte $(\mathrm{RME} / \mathrm{PBH})$, tendo como foco a formação docente. As produções acadêmicas levantaram muitas críticas em relação à formação "inicial" de professores. Muitos problemas também foram citados sobre a 
formação continuada dos profissionais do ensino e as limitações da escola como locus privilegiado dessa formação. Por fim, este estudo enfatizou as soluções encontradas na (pela) própria $\mathrm{RME} / \mathrm{PBH}$ para enfrentar os problemas relacionados ao desenvolvimento profissional de seus professores.

Palavras-chave: Formação continuada. Rede Municipal de Educação de Belo Horizonte. Estado do conhecimento.

\section{Abstract}

This article sought to analyze dissertations and thesis, defended between 1986 and 2005, about Belo Horizonte metropolitan school district, focusing upon teacher education. These academic works brought up a lot of critiques about pre-service teacher education. They emphasized also many problems at in-service teacher education and the limitations of school as a privileged place where teacher training might occur. Finally, this study highlighted too some of the solutions this School District has found in order to face problems related to its teachers' professional development.

Keywords: In-service teacher education. Belo Horizonte metropolitan school district. Literature review.

\section{Introdução}

Este artigo foi produzido a partir da pesquisa denominada $O$ estado do conhecimento sobre a Rede Municipal de Ensino de Belo Horizonte - 1986 a 2005, realizada pelo Núcleo de Pesquisa sobre Profissão Docente (PRODOC) da Faculdade de Educação da Universidade Federal de Minas Gerais (FaE/ UFMG). Dezenove investigações acadêmicas (três teses de doutorado e dezesseis dissertações de mestrado) foram lidas e analisadas, tendo como foco específico a formação docente.

Para empreender a análise dessas dissertações e teses, inicialmente um dos membros da equipe de pesquisa realizou individualmente uma 
leitura futuante (BARDIN, 1979) $)^{1}$ de todas esses trabalhos acadêmicos e, em seguida, produziu uma síntese, em que se explicitaram os objetivos de cada uma das pesquisas, o(s) seu(s) referencial(ais) teórico(s), sua(s) concepção(ões) de formação e os principais resultados. Realizaramse, então, sessões de leitura coletiva em que as sínteses dessas teses e dissertações foram confrontadas e tomadas como base para o levantamento de categorias. Estabelecidas as categorias, procedeu-se a uma reflexão sobre desdobramentos e limites dessas contribuições a partir de um aprofundamento na análise dos textos.

\section{Principais achados da pesquisa}

É nítida a concentração das teses e dissertações sobre a temática da formação docente a partir do ano de 2000. Apenas uma dissertação foi defendida antes desse período: em 1996. Todos os demais trabalhos acadêmicos foram concluídos em 2000 (três), 2001 (um), 2002 (seis), 2003 (quatro), 2004 (um) e 2005 (três), último ano abarcado pela pesquisa ${ }^{2}$. Observa-se que os anos de 2002 e 2003, sozinhos, foram responsáveis pela produção de mais da metade das pesquisas sobre o tema.

De maneira não surpreendente, há também um nítido enfoque sobre a formação continuada de professores em detrimento da "formação inicial". Em se tratando de uma rede pública (municipal) de ensino - e não de uma instituição de ensino superior - era mesmo de se esperar que a formação continuada - em vez da "formação inicial" - fosse a mais enfocada. A "formação inicial" foi foco de apenas uma dissertação, defendida em 2002.

Ao olharmos, historicamente, para o campo da formação docente, percebemos que a noção de "formação" foi, por muito tempo, restrita ao

\footnotetext{
${ }^{1}$ Leitura Flutuante consiste no primeiro contato do pesquisador com os documentos. É a leitura que permite o levantamento de hipóteses, de questões norteadoras e objetivos do trabalho, tendo em vista as teorias conhecidas

${ }^{2}$ Os dados apresentados para anos de 2004 e 2005 referem-se a pesquisas às quais tivemos acesso. Cerca de 20 dissertações e teses defendidas nesses anos, na FaE/UFMG, não haviam sido entregues, pelos autores, à biblioteca da instituição à época do levantamento das pesquisas (2006). A despeito de nossos esforços para obtê-las dos próprios autores, não tivemos acesso a elas. Por isso, acreditamos que o número de trabalhos sobre formação docente seja maior do que o apresentado pelos dados.
}

Rev. Diálogo Educ., Curitiba, v. 10, n. 30, p. 335-352, maio/ago. 2010 
atendimento a cursos de preparação "inicial" de professores nas universidades, nas instituições de ensino superior ou de ensino médio (curso normal). A ideia de que a formação de professores não termina com a conclusão de um curso preparatório, seja de nível superior ou médio, começou a ganhar mais força, no Brasil, a partir da segunda metade dos anos 80. A chamada "formação continuada" tornou-se expressão bastante conhecida a partir dessa época e a ideia da formação como um continum entre a formação "inicial" e a continuada passou a ser cada vez mais difundida nos meios acadêmicos. Isso talvez explique o porquê do aparecimento bastante tardio da temática formação docente entre as teses e dissertações sobre a RME/PBH: como visto, o primeiro estudo sobre o tema foi concluído apenas em 1996!

Quanto às metodologias adotadas nos estudos, tem-se o predomínio, quase absoluto, de abordagens de caráter qualitativo: estudos de caso, pesquisas narrativas (história oral etc.), etnografias etc. Quanto aos instrumentos de coleta de dados, predominaram as entrevistas individuais e semiestruturadas (narrativas biográficas), a observação direta, a análise de documentos, aplicação de questionários etc.

Em relação à concepção de formação, predomina a visão do aspecto "processual e centrada na prática docente". Ou, ainda, a formação docente continuada como um processo de formação humana, inscrito na constituição permanente do sujeito e que não se restringe somente ao seu aperfeiçoamento profissional (AZEVEDO, 2002). Os profissionais da educação são sujeitos da própria prática, da própria formação e, portanto, sujeitos da produção do conhecimento que circula no interior das escolas. Parte-se do pressuposto que a relação do sujeito com o conhecimento e a informação resulta de suas disposições construídas e ainda a construir ao longo de seu percurso de formação escolar e profissional (AGUIAR, 2002). E, finalmente, também aparece a visão de que a formação da identidade profissional é indissociável da formação da identidade pessoal (BAPTISTA, 1996).

A leitura das dissertações e teses sobre o tema da formação docente nos levou a dividir os principais achados da pesquisa em três partes, a saber:

1) críticas à formação "inicial" de professores;

2) críticas à formação continuada e as limitações da escola como locus privilegiado dessa formação; e, finalmente;

3) soluções construídas na (pela) própria RME/PBH. Em função do foco deste artigo, nos deteremos apenas sobre a segunda e terceira partes dos achados desta pesquisa. 


\section{Críticas à formação continuada e as limitações da escola como locus privilegiado dessa formação}

Os pesquisadores aqui estudados levantaram vários problemas em relação à formação "continuada" de professores no Brasil e explicitaram uma série de limitações da escola como locus privilegiado dessa formação.

O trabalho de Aguiar (2002), por exemplo, sobre a relação de professoras do ensino fundamental com as diversas fontes de informação, especialmente a internet, "aponta claramente para os limites da escola, como instância de conhecimento e saber, para alterar ou modificar, de maneira consistente, as disposições dos sujeitos acerca do conhecimento".

A dissertação de Baptista (1996, p. 179) demonstra que a cultura da escola influencia os processos de (de)formação das professoras alfabetizadoras. Ela levanta críticas às escolas pela falta de espaços para o desenvolvimento de trabalhos coletivos. Por via de consequência, há "dificuldades em estabelecer interlocução com os pares". Segundo a autora, na escola, predomina "um ritmo de trabalho individualizado o que colabora para acentuar sentimentos de rivalidade e de competição entre as professoras". A estrutura burocratizada das escolas "procura homogeneizar, fragmentar e hierarquizar as práticas e posturas pedagógicas".

Cabral (2005), ao estudar o processo de formação de "professoras leitoras", constatou que "a biblioteca da escola é pouco utilizada pelas professoras, que a consideram precária para as suas necessidades de leitura profissional e de lazer". A escola mostrou-se, segundo a pesquisa, "um lugar pouco propício para a leitura”.

\section{Soluções construídas na (pela) própria RME-PBH}

Além de apresentar várias críticas sobre a formação "inicial" e continuada de professores, as dissertações e teses sobre o tema da formação docente também apontam algumas soluções construídas na (pela) própria RME/PBH para o problema do desenvolvimento profissional dos professores. 


\section{A criação do Centro de Aperfeiçoamento dos Profissionais da Educação (CAPE)}

Rahme (2002) pesquisou a trajetória profissional de educadores da RME-PBH que atuaram como formadores de professores no Centro de Aperfeiçoamento dos Profissionais da Educação (CAPE), entre 1991 e 2000. Em seu trabalho, a autora analisa "as forças políticas que possibilitaram a emergência do CAPE como órgão implementador de uma política pública de formação docente em serviço". De acordo com Rahme, a proposta de criação desse Centro, em Belo Horizonte, "como uma medida de valorização profissional da escola pública municipal”, parte da ideia de que "um profissional da educação básica pode ser, também, um formador de professores". O espírito dessa proposta, destaca a autora, revela uma crítica implícita aos modelos tradicionais de formação - em geral, uma formação delegada a instâncias exteriores aos sistemas de ensino e de reconhecido saber - ao priorizar formadores advindos do chão da escola, conhecedores da realidade educacional do município e, presumidamente, mais capazes de atuar como condutores do processo de aperfeiçoamento profissional de seus colegas. Todavia, a autora nos faz lembrar que tal proposta desconsiderou as complexas questões implicadas na passagem de professor a formador.

Apesar dessa proposta priorizar "formadores advindos do chão da escola", contraditoriamente, a titulação acadêmica foi o critério de maior valorização na seleção dos candidatos a formadores do CAPE. Os dados coletados pela pesquisa mostram que as pessoas com maior tempo de Rede Municipal de Educação (RME-BH) apresentaram probabilidade menor de se integrarem ao CAPE, como formadores.

A visão de alguns professores, ao se candidatarem a formadores do CAPE, revelou "mais uma ocasião para sair da sala de aula do que para promover uma articulação entre docência e a formação em serviço". Aproximadamente $45 \%$ dos sujeitos que estavam na escola e foram para o CAPE não retornaram, imediatamente depois, à instituição escolar. Com isso, a perspectiva de contar com o regresso de um profissional mais qualificado à escola foi colocada em questão por desvirtuar um dos pilares fundamentais da proposta do CAPE: o fechamento do circuito escola/CAPE/escola.

Rahme (2002) explica que a experiência no CAPE, como formador, ao proporcionar ganhos de crescimento intelectual e de promoção 
simbólica, provocou nos sujeitos uma resistência em voltar a exercer suas atividades na escola, levando-os a buscarem caminhos considerados mais promissores para o seu futuro profissional. Segundo a autora, nota-se aí uma distorção na proposta do CAPE na medida em que a passagem por ele parece abrir para os sujeitos possibilidades mais atraentes do que o regresso à escola.

O trabalho de Rahme mostra-nos, em relação ao sujeitos que retornaram para as escolas após a experiência de trabalho no CAPE, o quanto essa experiência pode desencadear uma ampliação das possibilidades de compreensão do processo ensino-aprendizagem e de suas percepções sobre a profissão docente. Ou seja, a pesquisa demonstra que esses profissionais voltavam para a escola mais qualificados. Todavia, para alguns sujeitos, essa vivência foi permeada por um sentimento de insatisfação, seja no que se refere aos desafios presentes na atuação pedagógica na sala de aula, seja no que diz respeito às dimensões coletivas do trabalho escolar.

Finalmente, esse estudo revelou ainda que mudanças na gestão da Secretaria Municipal de Educação de Belo Horizonte (SMEd-BH) trouxeram desdobramentos para as atividades desenvolvidas pelo CAPE, entre elas: mudanças na direção da instituição, perda na sequência do trabalho realizado, alterações nas organizações dos grupos de trabalho.

\section{A experiência do Curso de Aperfeiçoamento da Prática Pedagógica (CAPP)}

Barros (2004) analisa uma proposta de formação continuada da RME-BH: o Cursos de Aperfeiçoamento da Prática Pedagóica (CAPP). A partir de 1995, segundo a autora, o CAPP deixou de ser um curso de formação continuada que visava a suprir falhas da formação inicial dos professores para se tornar um curso de aperfeiçoamento profissional para os docentes trabalharem dentro da proposta pedagógica implantada pela RME-PBH, a Escola Plural.

A autora apresenta um histórico do CAPP, de 1993 a 2003, destacando algumas mudanças estruturais e conceituais sofridas por esse programa de formação continuada. Ela afirma que, com a implantação da Escola Plural, o CAPP abandonou uma "concepção teórico-acadêmica da formação docente”, baseada na transmissão de teorias, dentro do modelo 
acadêmico, e "passou a valorizar os professores como sujeitos socioculturais e seus saberes experienciais" por meio de "reflexões sobre a prática docente e sobre novas formas para melhorar o trabalho pedagógico" (BARROS, 2004, p. 128). Pretendia-se, então, que "esse curso se tornasse um espaço de reflexão, análise e estudos para subsidiar a implantação da Escola Plural”. A formação continuada desenvolvida pelo CAPP deveria manter, então, uma estreita vinculação entre a formação e a profissão.

Dessa maneira, e a partir dessas mudanças, o CAPP passou a conceber "o professor como sujeito de sua própria formação" sendo ele o responsável por conduzir seu aprimoramento. "O objetivo do curso é formar o professor autônomo, observador, pesquisador de sua própria prática, para que as escolas cheguem a um nível tal de autonomia e desenvolvimento pedagógico que não precisem mais do CAPE" (BARROS, 2004, p. 129).

A intenção do CAPP passou a ser, então, a de "criar um vínculo estreito com o projeto pedagógico da escola" e "manter um diálogo permanente com o coletivo das escolas". Além disso, de acordo com os formadores do CAPP, o curso foi elaborado com o propósito de ampliar a visão dos professores sobre a educação; desenvolver trocas de experiências entre os professores; propiciar aos docentes acesso a conhecimentos, trabalhos e atividades realizados em outros espaços (universidades, cinemas, teatros, sindicatos etc.); sistematizar e valorizar os saberes adquiridos pelos docentes ao longo de sua vida pessoal e profissional; propiciar o questionamento da prática docente; fazer do CAPP um espaço de articulação da categoria docente para reivindicação dos seus direitos trabalhistas; além de discutir a proposta da Escola Plural.

Por meio do depoimento de alguns professores participantes da pesquisa, a autora constata que o curso proporcionou uma oportunidade de trocas de experiências e ideias com os colegas da RME/PBH e de reflexão sobre o seu próprio trabalho. $\mathrm{O}$ intercâmbio entre os docentes possibilitou que o professor reconhecesse e valorizasse o seu saber experiencial. Mesmo com as dificuldades dos professores de fazerem registros da prática de maneira sistematizada, a pesquisa constata que o CAPP auxiliou os docentes na reflexão de sua própria prática.

Apesar das análises positivas que a autora faz sobre essa experiência, ela não parece estranhar uma concepção de formação, muito criticada na literatura especializada, a do professor como "multiplicador das discussões, dos estudos e das práticas do curso no seu espaço de trabalho”, no qual 
se espera "que o professor repasse para o coletivo da escola o que ele está aprendendo" nesses cursos. Os próprios depoimentos dos professores demonstram que esse objetivo do curso não foi alcançado.

\section{Limites e possibilidades da utilização do "tempo não letivo" como espaço/tempo de desenvolvimento profissional}

Com o propósito de investigar o processo de apropriação da Escola Plural pelos docentes da RME/PBH, Soares (2000) analisa o "tempo docente", especificamente o "tempo não letivo", ou seja, "período de tempo que os docentes dispõem dentro de sua jornada de trabalho para atividades fora da sala de aula (atividades de planejamento, estudo, formação, entre outras)" e "para a elaboração de um trabalho coletivo".

A pesquisa sugere que esse tempo/espaço (especificamente, ela se refere à chamada "reunião do $3^{\circ}$ ciclo"), em que emergem os discursos sobre as práticas e, por meio deles, as concepções que orientam o trabalho educativo, "se configura como um momento importante de trabalho coletivo". Todavia, a autora chama a atenção para o fato de a existência desse tempo/espaço não garantir, por si só, a consolidação de um processo de desenvolvimento profissional. Para que isso ocorra, se faz necessário que os/as professores/as o concebam como tal.

A autora esclarece que, para os docentes, os "tempos não letivos" são "momentos para planejar, construir projetos e atividades integradas, discutir soluções para os problemas que surgem no cotidiano de seu trabalho". Essas atividades, segundo a pesquisadora, comportam, indubitavelmente, uma dimensão formativa, pois "provocam interações nas quais os docentes socializam conhecimentos, questionam e re-significam suas ações, seus valores, estabelecem relações de colaboração, constroem novas sensibilidades". Todavia, Soares pondera que essas atividades "contribuem limitadamente para o processo de desenvolvimento profissional”, ou seja, elas "não resultam de uma ação formativa consciente e deliberada, que incorpore o exercício sistemático de refletir criticamente sobre a prática". E isso acontece porque tais atividades "não potencializam os docentes para pensar e problematizar os fundamentos e pressupostos de seu trabalho e para se apropriarem dos conhecimentos que constroem no seu fazer cotidiano". Ainda de acordo com o argumento da autora, as atividades desenvolvidas nas 
reuniões e tempos coletivos evidenciam uma visão pragmática do trabalho docente - trabalho centrado em um fazer imediatista - pouco afeito a preocupações e fundamentos, e com a articulação entre estes, as intenções educativas definidas para cada ciclo e as aprendizagens dos alunos. Por fim, Soares afirma que a ênfase nessa dimensão instrumental perpetua a dicotomia teoria e prática, dificultando que esses tempos se consolidem como espaços de formação permanente do professorado no interior da escola.

A autora enfatiza, então, "a necessidade de se instituir, no interior da escola, a cultura do estudo, da investigação e da reflexão teórica”. Porém, a pesquisa mostra que esse é um grande desafio. A investigação revelou que “a prática de fazer leituras e estudos, de buscar fundamentos teóricos para uma melhor compreensão da ação pedagógica e sua transformação, presente nos primeiros anos de funcionamento da escola pesquisada," se perdeu com o tempo. A pesquisadora observou que, "durante as reuniões do $3^{\circ}$ ciclo, os docentes, absorvidos no planejamento e realização de trabalhos, de projetos, nas discussões sobre os problemas da escola, não destinavam tempo para leituras, estudos, pesquisas, aprendizagens conjuntas". Dessa maneira, a autora argumenta que "fundamentar a reflexão sobre a prática, ou seja, atrelar esse exercício a um aprofundamento teórico, implica em uma recontextualização do trabalho docente". E isso "esbarra em uma realidade que apresenta aspectos concretamente desfavoráveis à sua realização". Soares chama atenção para as condições de trabalho docente marcadas, entre outros aspectos, pela sobrecarga de tarefas e aumento das exigências e expectativas sociais depositadas na escola no que se refere à educação das crianças e dos adolescentes; pelo desestímulo quanto à perda de prestígio social e poder aquisitivo; pelas condições estressantes do trabalho na escola e na sala de aula.

Soma-se aisso a pouca familiaridade que, de um modo geral, o docente do ensino básico tem com o universo da pesquisa e da produção teórica, não apenas no campo educacional, mas também na área do conhecimento à qual se vincula como professor(a) de uma disciplina (SOARES, 2000). A autora insiste nessa questão com o objetivo de enfatizar a relevância dos saberes científicos para a construção de um olhar crítico e reflexivo sobre a prática e, ao mesmo tempo, denunciar sua inexpressiva importância no interior da escola. Todavia, reitera a necessidade de igualmente conferir à prática e aos saberes dela decorrentes, estatuto epistemológico próprio, reconhecendo-a como portadora de valor social equivalente ao da teoria. 


\section{A implementação da "Rede de Trocas": a troca de experiência como alternativa de formação continuada}

A dissertação de Azevedo (2002, p. 23) dedica-se ao estudo da chamada "Rede de Trocas", ou seja, estratégia de formação docente, desenvolvida pelo CAPE - Centro de Aperfeiçoamento dos Profissionais da Educação da RME-PBH - que utiliza o relato de experiência como instrumento de formação de professores. Trata-se de "apresentação de uma narrativa oral e escrita de experiências de professoras e escolas na tentativa de organizar a vida escolar e equacionar problemas pedagógicos". Dessa maneira, "se refere tanto ao processo de elaboração do relato de experiências escrito, quanto ao evento de apresentação pública do relato oral". Os textos produzidos pelos docentes foram posteriormente editados na forma de "Cadernos de Relatos" e "distribuídos às escolas da RME/BH, depois do evento Rede de Trocas".

Em relação às constatações da pesquisa, destacam-se: o alto grau de interferência dos gestores do CAPE na produção dos relatos escritos dos professores, o que representou uma "tentativa de controle" sobre essa produção, chegando a significar até mesmo "certa censura" sobre o conteúdo dos relatos. Criticou-se, por exemplo, a "Rede de Trocas" como um "espaço de divulgação unicamente voltado às experiências que deram certo, com uma supervalorização dos resultados positivos". No que tange à organização da "Rede de Trocas", o relacionamento dos gestores das Regionais com os gestores do CAPE mostrou-se bastante tenso e hierarquizado, em que os gestores do CAPE se responsabilizavam pelas decisões finais.

Azevedo (2002, p. 24) percebe uma certa tendência de "padronização das condições dadas às escolas para a produção de seus relatos escritos, tanto em termos de tempo quanto ao formato dos Cadernos de Relatos". A autora considera que tal padronização "pode ser um fator de interferência negativa" sobre o produto final. Segundo ela, "relatos de experiências pedagógicas diferenciadas podem exigir tempo e recursos diferenciados para serem construídos".

Esses problemas acabaram interferindo na participação dos professores na "Rede de Trocas". Muitos professores "desconfiavam das verdadeiras intenções dos gestores". Alguns "achavam que seu trabalho poderia ser apropriado e usado como propaganda de governo". Esses se sentiam usados quando os avanços educacionais alcançados, por meio de 
seu trabalho, eram reconhecidos pela SMEd, porém, sem que isso resultasse em melhorias em suas condições de trabalho. Daí um certo ressentimento por parte dos docentes em relação ao "discurso oficial" que "valoriza sua iniciativa criadora, ao mesmo tempo em que desenvolve métodos de controle cada vez mais rígidos do trabalho docente" (AZEVEDO, 2002, p. 60).

Apesar dessa tensão entre as escolas e a SMEd, a maior parte das escolas convidadas aceitou fazer parte da "Rede de Trocas" por acreditarem ser essa participação questão mais importante do que a possibilidade de serem usadas politicamente pela SMEd. Reconheciam, no relato de experiência, a oportunidade de dialogar com colegas da Rede Municipal de Educação.

Azevedo (2002) destaca, então, a importância da construção do relato para os professores. Ao organizarem suas ideias para se fazer o relato - seja ele oral ou escrito -, os sujeitos reconstroem suas experiências de forma reflexiva e, portanto, acabam fazendo uma autoanálise das próprias práticas, o que cria novas bases de compreensão destas.

Todo o processo de produção dos relatos escritos, sua sistematização final por meio dos "Cadernos de Relatos", e de sua apresentação oral, revelou-se como um recurso importante na formação docente à medida que pode estimular a reflexão dos professores sobre suas práticas e sobre os contextos em que elas se realizam, contando-as, explicando-as e trocandoas com seus pares.

O momento de elaboração dos relatos escritos revelou-se uma etapa muito importante em função do esforço de se produzir uma narrativa sobre as experiências docentes e, ao mesmo tempo, significar uma oportunidade de eles interpretarem e analisarem suas ações e também perceberem onde e como modificá-las. A escrita do relato também fez emergir sentimentos relacionados às diversas situações que os docentes vivenciaram no cotidiano escolar e isso constituiu-se em um aspecto muito relevante para o "processo de conhecimento dos sujeitos sobre si mesmos e suas ações".

O evento de apresentação dos relatos orais na "Rede de Trocas" também foi muito importante para os professores, pois permitiu o contato entre as diversas escolas da RME-BH e, por via de consequência, o conhecimento sobre as diferentes formas de trabalho dos professores municipais, ou seja, como eles enfrentavam problemas considerados comuns, favorecendo, enfim, a divulgação das diferentes maneiras de se resolver ou lidar melhor com alguns problemas do cotidiano escolar. Além 
disso, ao terem seus trabalhos apresentados publicamente, os professores se sentiam valorizados por perceberem que suas ideias eram reconhecidas como saberes docentes.

Mesmo assim, a autora adverte que "os processos de produção de relatos escritos para a Rede de Trocas parecem ter sido menos formativos do que outros" (AZEVEDO, 2002, p. 24). Isso porque "não houve envolvimento do coletivo de professores nessa tarefa e a eles não foram dadas condições de contarem suas estórias como queriam". Houve, em alguns casos, uma centralização excessiva dos relatos pela equipe pedagógica das escolas convidadas (diretoras, vice-diretoras e coordenadoras pedagógicas), fazendo com que os professores atuassem como meros coadjuvantes. Ainda segundo Azevedo, os gestores do CAPE podem ter sugerido que "as pessoas que ocupam funções de gestão estão mais aptas a falarem sobre o trabalho desenvolvido nas escolas, idéia que contraria os objetivos dessa atividade".

Mesmo assim, aos olhos dos professores participantes da pesquisa, a "Rede de Trocas" foi vista como uma oportunidade de os professores entrarem em contato com os colegas de outras escolas da RME-BH, conhecerem mais sobre os trabalhos uns dos outros, aprofundar as discussões sobre eles, de obter respostas mais claras e objetivas para as suas dúvidas e conversar com especialistas sobre questões difíceis para os professores. Tal iniciativa representou, na visão dos docentes, um momento dedicado "a favorecer o diálogo entre os professores da RME-BH sobre aspectos como currículo, gestão de tempos e espaços escolares, a reflexão sobre suas práticas e a discussão de problemas comuns".

Além disso, esse espaço representou um momento em que os professores eram "mostrados de maneira positiva, como profissionais capazes, criativos e dedicados". Segundo a pesquisadora, a "Rede de Trocas" pode contribuir para "a redução dos medos e e preconceitos entre os professores". Esse espaço representou "um momento que trouxe alívio para algumas angústias" dos professores.

Esses mesmos professores, participantes da pesquisa, sugeriram a continuidade e a ampliação da "Rede de Trocas" na SMEd (um pequeno número de professores teve acesso à Rede de Trocas, em geral) e que esses espaços deveriam ser oferecidos com outros tipos de ações "de complementaridade". Sugeririam ainda o aumento do tempo destinado ao debate na "Rede de Trocas" pois, segundo eles, "o relato de experiência deve priorizar a compreensão do que é narrado e a maneira como ele pode 
interagir" com o público do evento. Há um desejo dos docentes que "a Rede de Trocas seja um instrumento por meio do qual se possa buscar, coletivamente, novas formas de se trabalhar". Demandou-se também a "necessidade de ampliação do público da Rede de Trocas".

Em um outro trabalho de destaque, entre as teses e dissertações analisadas, Damasceno (2002) também se interessou pelo tema da "troca de experiência" como alternativa de formação continuada e como uma das maneiras mais utilizadas pelos professores na construção de seus saberes profissionais. A autora compreendeu o termo "troca de experiência" como o processo de partilha de valores, estratégias, saberes, materiais, exclusivamente entre os/as professores/as, em situações formais previamente programadas (momentos coletivos nas escolas, tais como, as reuniões, seminários, o Conselho de Classe, as reuniões pedagógicas) ou em situações informais (encontros no corredor, no pátio, na cantina, em momentos de intervalo na sala dos professores, antes e após as reuniões, debates, palestras, seminários, durante as festas e comemorações, nas conversas pelo telefone, no trajeto das caronas, nas conversas em chats, listas de discussões e fóruns virtuais).

Entre os saberes passíveis de troca, a autora destaca aqueles referentes: à cultura da escola (rituais, cerimônias, comemorações, exigências quanto ao cumprimento de normas e regulamentos), à sua organização administrativa (sistema de gestão - processo de eleição e funcionamento da direção, da coordenação e do colegiado escolar - a relação com a legislação nacional e local, acesso a equipamentos, à secretaria, à biblioteca, à cantina e a avaliação de desempenho), aos recursos pedagógicos utilizados (organização dos tempos docentes e discentes e o sistema de avaliação, uso de equipamentos e materiais, recursos de ensino - manejo de classe) e aos conteúdos curriculares desenvolvidos (sugestões, conselhos, orientações sobre a seleção do conteúdo a ser desenvolvido, a ordem a ser observada no desenvolvimento do mesmo, a articulação das áreas de conhecimento, a interdisciplinaridade e os tipos de avaliação).

Damasceno (2002) divide e categoriza as "trocas de experiências" em dois tipos: "trocas que constituem um processo de construção de saberes profissionais" e "trocas que se resumem à aquisição de truques profissionais para se desvencilhar de situações consideradas árduas e difíceis". A autora esclarece que "truques" são maneiras "eficientes de resolver problemas profissionais que podem, por vezes, concretizar em mecanismos que ferem 
princípios éticos e pedagógicos da educação, constituindo um caminho fácil para resolver problemas pedagógicos e administrativos".

Por meio da pesquisa, Damasceno (2002) levantou também uma série de fatores que inibem a troca de experiência no interior da escola. Segundo ela, esses fatores inibidores são de diferentes naturezas: pessoal, profissional, cultural e organizacional. São eles: a falta de entusiasmo ou síndrome do burnout, a cultura do individualismo, o medo, a insegurança e o mal estar dos professores, o sentimento de ausência de formação, o problema da competência não utilizada e da incompetência negligenciada, a resistência pessoal e institucional, o desconhecimento dos saberes dos professores, a inadequação dos tempos e espaços escolares, a sobrecarga de trabalho e a gestão da unidade.

A autora acredita no potencial da "troca de experiência" para alterar uma situação de pouca colaboração entre os professores na escola. Todavia, Damasceno não defende a institucionalização de espaços de "troca de experiência" nas escolas. Segundo ela, paradoxalmente, tal institucionalização pode contribuir para a inibição desse processo. A autora levanta, então, as seguintes questões: A institucionalização das trocas não estaria despojandoas de grande parte de sua riqueza, espontaneidade e imprevisibilidade e deslocando-as do controle do/a professor/a para o controle daqueles que a organizam? E, a formalização da espontaneidade não estaria, pois, levando as trocas a migrarem do espaço informal e instituinte para o formal e instituído, desaparecendo da escola?

A autora sugere, finalmente, mudanças no ámbito do sistema educacional, em que "énecessário uma gestão que revele mais um investimento na qualidade social da educação do que investimentos administrativos de controle de pessoal"; no âmbito da escola, em que "é necessário um investimento na construção de um projeto político-pedagógico que explicite as intenções e os objetivos comuns da instituição, possibilitando práticas coerentes e estimulando investimentos coletivos"; e individualmente, em que "os professores precisam reeducar seu olhar pedagógico, acreditando mais em sua competência, reconhecendo que é na sua prática que se constrói uma nova identidade e o compromisso social e político com a educação escolar".

À guisa de conclusão, a autora reforça a ideia de que a escola não pode mais se esquivar da criação de espaços coletivos em que se discutam as representações dos professores acerca da formação continuada. Nos seus 
dizeres, "É preciso construir com os professores e não para os professores projetos de formação nos quais eles se vejam como produtores de saberes, resgatando seu lugar de mestre para que eles passem a arriscar a encontrar respostas para suas incertezas, em vez de se entregarem à inibição, ao silêncio e até mesmo ao abandono da profissão".

\section{Conclusões}

O presente estudo procurou sistematizar e analisar as teses e dissertações produzidas, entre 1986 e 2005, sobre a Rede Municipal de Educação de Belo Horizonte, tendo como foco a formação docente.

Como resultado desse levantamento, encontraram-se 19 teses e dissertações defendidas, nesse período, sobre a temática da formação de professores na RME-BH. Percebeu-se, como já era de se esperar, o predomínio quase absoluto de pesquisas sobre a formação continuada de educadores. Por se tratar de uma rede municipal de ensino e não de uma instituição de ensino superior, tal constatação não representa, de maneira alguma, uma surpresa.

As leituras flutuantes das teses e dissertações, as produções das sínteses, suas leituras coletivas e as análises subsequentes revelaram que essas investigações acadêmicas levantaram muitas críticas em relação à formação "inicial" de professores. Muitos problemas também foram citados sobre a formação continuada dos profissionais do ensino e as limitações da escola como locus privilegiado dessa formação. Por fim, este estudo enfatizou as soluções encontradas na (pela) própria Rede Municipal de Educação de Belo Horizonte para enfrentar os problemas relacionados ao desenvolvimento profissional de seus professores.

Esta pesquisa revela, por um lado, que a RME/PBH acumulou, ao longo desses últimos quinze anos, grande experiência em relação ao desenvolvimento profissional de seus educadores, por meio da implantação de diferentes políticas, ações e iniciativas de formação continuada. Por outro lado, este mesmo estudo parece indicar um problema grave a ser enfrentado pela RME-BH: a falta de continuidade dessas políticas, ações e iniciativas em prol do desenvolvimento profissional dos professores. Além disso, as investigações acadêmicas aqui analisadas denunciam que a grande hierarquização na implantação dessas iniciativas e a não garantia de condições de trabalho docente nas escolas tornam o impacto dessas ações bastante limitado. 
Por fim, a concentração dessas investigações acadêmicas a partir do ano 2000 revelou que se trata de uma temática bastante recente entre as teses e dissertações sobre a Rede Municipal de Educação de Belo Horizonte. Isso nos faz pensar que novos trabalhos sobre o tema da formação docente devem ter sido concluídos a partir de 2005 e que não fizeram parte do levantamento desta pesquisa. Caso isso seja confirmado, nos colocaríamos diante de uma situação que exigiria a continuidade desse estudo do tipo "estado do conhecimento" sobre a RME-BH, a partir do ano 2005.

\section{Referências}

AGUIAR, A. M. de S. A relação de professoras do ensino fundamental com o conhecimento e a informação: das orientações familiares aos investimentos atuais. 2002. 137 f. Dissertação (Mestrado em Educação) - Faculdade de Educação da Pontifícia Universidade Católica de Minas Gerais, Belo Horizonte, 2002.

AZEVEDO, A. L. de F. Rede de trocas: um estudo sobre os significados de narrativas de experiências na formação docente. 2002. 176 f. Dissertação (Mestrado em Educação) - Faculdade de Educação da Universidade Federal de Minas Gerais, Belo Horizonte, 2002.

BAPTISTA, M. C. A (de)formação da professora alfabetizadora. 1996. $241 \mathrm{f}$. Dissertação (Mestrado em Educação) - Faculdade de Educação da Universidade Federal de Minas Gerais, Belo Horizonte, 1996.

BARDIN, L. Análise de conteúdo. Lisboa: Setenta, 1979.

BARROS, K. de O. S. As intencionalidades e os desdobramentos do CAPP no trabalho dos professores da Rede Municipal de Ensino de Belo Horizonte. 2004. 263 f. Dissertação (Mestrado em Educação) - Faculdade de Educação da Universidade Federal de Minas Gerais, Belo Horizonte, 2004.

CABRAL, A. N. M. Professoras leitoras nos anos inicias do ensino fundamental: procurando entender as determinações desse processo. 2005. 163 f. Dissertação (Mestrado em Educação) - Pontifícia Universidade Católica de Minas Gerais, Belo Horizonte, 2005. 
DAMASCENO, A. R. Da formação no corredor ao corredor de formação: a troca de experiências como alternativa para a gestão dos dilemas e desafios da prática pedagógica de professores de Língua Portuguesa. 2002. 201 f. Dissertação (Mestrado em Educação) - Faculdade de Educação da Universidade Federal de Minas Gerais, Belo Horizonte, 2002.

RAHME, M. M. F. Trajetórias profissionais de educadores e formação em serviço: o caso do CAPE (1991-2000). 2002. 186 f. Dissertação (Mestrado em Educação) - Faculdade de Educação da Universidade Federal de Minas Gerais, Belo Horizonte, 2002.

SOARES, C. C. Construindo a escola plural: a apropriação da Escola Plural por docentes do $3^{\circ}$ ciclo do ensino fundamental. 2000. 201 f. Dissertação (Mestrado em Educação) - Faculdade de Educação da Universidade Federal de Minas Gerais, Belo Horizonte, 2000.

Recebido: 22/03/2009

Received: 03/22/2009

Aprovado: $10 / 05 / 2009$

Approved: 05/10/2009 